\title{
Understanding Students' Resistance to Autonomous Learning in an L2 English Language Course at a University in Lebanon
}

\author{
Khairallah, M. \\ Fleonova, 0. \\ Nicolas, M. 0.
}

\section{Abstract}

This qualitative research investigates students' resistance to autonomous learning activities in an English language course at a university in Lebanon. Data was gathered across four sections of English 101 based on observations of 68 students, focus group discussions and two teachers' reflective diaries. Thematic analysis yielded that students showed signs of resistance during collaborative learning, metacognitive activities, and the evaluation process. The students were also unwilling to independently use available language learning resources. The data suggested that the possible causes of resistance lay in the mismatches between students' expectations and the course design, the learning cultures that the students bring to the classroom, and students' perceptions of the place English holds both at the university and in their lives. This study reveals that expressions of resistance during classroom interactions resonate with the complex and layered nature of English language learning.

Keywords: learner autonomy, resistance to autonomous learning, English language teaching in Lebanon, learning cultures, second language learning

\section{Introduction}

Autonomy has become an important attribute of the 21st century learner who is expected to be prepared for the fast-changing requirements and challenges of academic and professional life. Research in the teaching of English in L2 classrooms shows a relationship between students' language learning proficiency and autonomous learning (Balçikanli, 2010; Benson, 2001; Benson \& Voller, 1997; Borg \& Alshumaimeri, 2019; Chik, Aoki, \& Smith 2018; Dafei, 2007; Garcia-Carbonell, Rising, Montero, \& Watts, 2001; Harmer, 2001; Nunan, 1997; Pawlak, MystkowskaWiertelak, \& Bielak, 2017; Po-Ying, 2007; Schormová, 2017). The practical applications for fostering autonomy in the classroom lie in adopting teaching methodologies promoting active learning and redesigning syllabi and assessment models in accordance with the principles of autonomy (Balçikanli, 2008; Weimer, 
2013). Classroom practice, however, shows that learners are not always able or prepared to embrace a greater responsibility for their own learning. Many studies in the L2 tertiary classroom reflect different moments of tension or resistance when active methodologies that promote autonomy are introduced (Bloom, 2007; Canagarajah, 1993; Jing, 2006; Miller \& Zuengler, 2011; Stover \& Holland, 2018; Walton, 2011).

More context-specific qualitative studies that explore the complexities of such related concepts as autonomy, self-regulation, self-access learning, self-direction and language learning strategies are encouraged (Rose, 2012). This study explores the manifestations and possible causes of learners' resistance to autonomous learning in an English course at a university in Lebanon. In order to better understand the complexity of resistance, this qualitative research is designed around the following research questions:

How does student resistance to autonomous learning manifest in the classroom?

What are the possible causes of student resistance to autonomy in a language classroom?

\section{Literature Review}

Autonomy and resistance in language learning

\subsubsection{Autonomy in L2 classrooms}

The concept of autonomous learning in language classrooms has evolved since the mid-1970s. The most widely quoted definition of autonomy is the 'the ability to take charge of one's own learning' (Holec, 1981, 3). It was soon realized that Holec's definition could not be applied to all learning situations, and learners could not be decision makers in all the areas of the learning process, as initially suggested, such as determining the objectives, content, methods, pace and time, and evaluation of their learning (Smith, 2008). Since the early 1990s learner autonomy has increasingly become a part of classroom pedagogy. In the classroom setting, as a social context for learning, teachers play a supportive role aiding students in the development of that skill (Benson, 2001, 2006). This form of socially mediated interdependent learning (Little, 2003) fosters learner autonomy both as a psychological attribute and practical ability. Through guidance toward autonomy the students develop 'a capacity and willingness to act independently and in cooperation with others, as a social, responsible person' (Dam et al., as cited in Smith, 2008, 396). This definition comes closest to how autonomy is understood in this study.

In language teaching, autonomy has become an intrinsic element in learner-centered approaches (Borg \& Alshumaimeri, 2019; Little, Ridley \& Ushioda, 2003; Nunan, 1997; Weimer, 2013) where students take on a more active role in their learning; students collaborate to participate in task based activities, for example, simulations (Crookall \& Oxford, 1990; Jones, 1982; 1995; Sallies, 2002; Schormová, 2017); they 
develop their own language learning strategies (Oxford, 2017); they employ technologies and explore digital practices to develop their capacity to take control of their own learning trajectories (Chik, 2018, Jones, 2018); they critically reflect on their learning and engage in self-assessment activities (Little, 2005). The teacher's role changes from an authoritative provider of information to a facilitator and guide (Garcia-Carbonell et al., 2001).

Many scholars warn that concerns about developing strategies for learner autonomy should not overshadow broader critical-political concerns, or larger social and educational goals of autonomy (Benson 1997, 2009; Holliday, 2003; Pennycook, 1997). Shmenck (2005) argues that the cultural aspects of the term need to be given serious consideration and cautions that educators run the risk of 'cultural blindness' if they neglect the specific cultural situations where autonomous learning is introduced. Autonomous learning is not a neutral process but one that is embedded in power issues within the classroom setting and the broader social context (Benson, 1997, 2009; Oxford, 2003; Pennycook, 1997; Shmenck, 2005).

\section{Resistance to change}

Students' acceptance of innovations in classroom methodology is usually taken for granted by course designers. However, students might resist teaching innovations when the change requires that they readjust their perceptions of learning and of the roles teachers and students play in the process (Keeney-Kennicutt, Gunersel \& Simpson, 2008; Stover \& Holland, 2018; Walton, 2011). Students often enact resistance to change in their learning environments, either overtly or in less direct ways. Researchers describe learner resistance as opposition, oppositional behaviors, oppositional attitudes, tension, or reluctance (Bloom, 2007; Canagarajah, 1993; Jing, 2006; Miller \& Zuengler, 2011; Stover \& Holland, 2018; Walton, 2011). English language classrooms are 'potential sites of resistance as complex language and cultural ideologies come together and often result in conflict' (Miller \& Zuengler, 2011,133). Specific occurrences of resistance include making the classroom disorderly through interruptions, challenges and disagreements, feigning misunderstanding of what is required of them, 'forgetting' to complete or turn in an assignment, 'playing dumb', rolling eyes, emotional outbursts, bargaining, or even boycotting English classes as a response to innovation in classroom methodology (Blidi, 2017; Miller \& Zuengler, 2011; Shamim, 1996; Vetter, Reynolds, Beane, Roquemore, Rorrer \& Shepherd-Allred, 2012; Walton, 2011). Resistance can occur because of differing definitions and visions of the learning process.

A number of studies explore various causes of learner resistance to autonomyoriented classroom methodologies. One such cause is the mismatch between the course expectations and the students' expectation of language learning. While the course might prioritize and emphasize process learning, learning strategy training, reflective learning, metacognitive learning, and co-construction of knowledge during collaborative work, students might be oriented towards tangible language 
achievements important in traditional assessment and product-oriented educational contexts (Canagarajah, 1993; Jing, 2006; Little, 2003). In Tsang's study (as cited in Jing, 2006, 97) students 'did not ask for autonomy but for the acquisition of particular language skills' to see tangible short-term results and 'they did not see the gaining of autonomy as relating to their progress towards their learning goal'. Interpersonal problems and imbalances of responsibilities during group work can also lead to students' skepticism and resentment (Hill, 2009; Jung \& Levitin, 2002). The methodology itself, like for example simulations, might not be perceived by some students as 'serious learning' and might provoke students' mistrust and resistance (Hill, 2009; Jung \& Levitin, 2002). Although some students realize the importance of English for their lives they often see little relevance of a language course other than satisfying the academic requirements of the institution (Canagarajah, 1993; Jing, 2006).

Student unpreparedness for autonomous learning might be a result of previous educational experiences (Balçikanli, 2008). Years of teacher-centered instruction have produced students who have 'little or no commitment to learning ... unable to function without structure and imposed control' (Weimer, 2013, 146). The situation results in teachers perpetuating the cycle of passivity by continuing to create and teach courses that suit students who are used to inactivity. Because of previous educational experience learners believe that 'a highly teacher-directed approach is the way education should happen' and 'are simply not aware of the power they possess as learners' (Hiemstra \& Brockett, 1994, 91). Weimer (2013) provides some common sources of student resistance during the transition from the so-called traditional classroom to a more active one: reluctance to do more work which learnercentered approaches require; fear of being outside their comfort zone; feeling threatened by unfamiliar tasks and expectations. Successful in the other learning paradigm, students might perceive a threat to their academic achievements; overall, 'classrooms where teachers make all the decisions are safer, simpler places' (Weimer, 2013, 204).

The cultural context in which learning takes place can afford or constrain the fostering of autonomy (Blidi, 2017; Cortazi \& Jin, 1997, 2013; Jin \& Cortazzi, 2017; Palfreyman \& Smith, 2003). The authority structures of the community outside the classroom might influence students' cultures of learning and lead to the acceptance or rejection of innovations in autonomy-oriented classroom (Shamim, 1996). Resistance to autonomy might also be determined by the institutional context (Blidi, 2017; Stover \& Holland, 2018; Tolman \& Kremling, 2017). Resistance to autonomy in English language classrooms might stem from issues of power of English as an international language and a language of dominance (Pennycook, 1997).

\subsection{Language Learning in the Lebanese Context}

A Lebanese student is a product of complex cultural, religious and socio-political factors (Bacha \& Bahous, 2011; Zakharia, 2011). Although Arabic is the mother 
tongue and the official language of the country, the foreign languages of English and French coexist with Arabic in daily interactions and importantly in the educational sector. The majority of the population is bilingual or even tri-lingual. For a few decades French and Arabic were the official languages as a result of the French Mandate over the country from 1920-1943. Since the 1990s, with the internationalization of education, English has decidedly become the lingua franca of Lebanese tertiary level education (Annous, Nicolas \& Townsend, 2017; Gill \& Kirkpatrick, 2013) with around 30 universities using English as the medium of instruction (Ministry of Education and Higher Education, 2016).

Students entering the university come from a wide array of schools from governmentsupported public schools to privately owned self-managed religious or secular schools, either with English-Arabic or French-Arabic medium of instruction. The learning culture in both 'is characterized by the dominance of teacher-centered teaching approaches' (Lebanese Association for Educational Studies, 2006, 17). As a result, in general, most students have been trained in rote learning (Daouk, Bahous \& Bacha, 2016). The official exit examination required by the Ministry of Education for all Lebanese high school students, the Lebanese Baccalaureate, compels students to memorize vast amounts of content in order to successfully pass the exam (Akar, 2012). The complex culture that learning English brings into the Lebanese classroom is rarely discussed, and further studies of resistance in the classroom need to take these complexities into consideration.

\section{Research Methodology}

This exploratory qualitative study investigated students' resistance to autonomous learning activities using three methods of data collection:

Unstructured Observation: The two non-participant observers from outside the English Department observed for one to two hours per week over the 15 weeks. They kept observation notes on all classroom interactions that dealt with autonomous activities, group work and debriefing reflection sessions. The observers recorded any classroom interaction or discussion without any foreseen or structured criteria, but they were particularly focusing on instances of resistance to autonomous activities. The excerpts from observations are labelled $10 \mathrm{~N}$ for Observer One and $20 \mathrm{~N}$ for Observer Two with the observation number following, for example 10N16.

Teachers' Diaries: The two teacher-researchers kept record of each class session over the 15 weeks. They took brief notes during the class time and then spent 20 minutes after each class recording verbal and non-verbal student behavior. They also re-called excerpts of student-student, students-teacher, students-teacher-class conversations that dealt with autonomous activities. Once the classroom interactions were noted, they reflected on each session (Maharaj, 2016) noting down their thoughts, feeling, impressions and insights. The excerpts from the teachers' diaries are labelled 1TD for 
Teacher One and 2TD for Teacher Two with the class session number following, for example 2TD26.

Focus Group Discussions: Students of the four sections voiced their position during a focused discussion at the end of the semester in which they reflected on their progress in the course, on their perceptions of autonomy and their interpretations of the possible causes of resistance. Students were divided into 4 groups of 4-5 students per section. The observers recorded the interactions of the group, while the teachers facilitated the discussion. Students' quotes from the focused group discussions are labelled according to the student participant who was assigned a number, for example FGS13.

\subsection{Context and Participants}

This study took place in a private university in Lebanon where English is the medium of instruction. The observed classes had between fifteen and eighteen students each; sixty-eight in total. The students were roughly divided between male and female. The students were either bilingual (English-Arabic) or trilingual (English-Arabic-French). Students had been informed about the research at the beginning of the semester, consent letters were signed and permission to conduct the research was granted.

English 101 required a shift from a teacher and textbook centered classroom to an active learning environment that demanded self-motivated autonomous learners capable of working in cooperating teams and engaging in simulation activities, reflective learning and metacognitive development. This active methodology was made explicit in the syllabus, which stated, "Through individual and collaborative work, students in English 101 are expected to become responsible autonomous learners who can find their own strategies for learning.'

\subsection{Data Analysis}

A thematic analysis was carried out through an iterative process. The researchers reviewed, sorted, reflected on and coded the collected data from the diaries and observations first individually and then collaboratively. Representative quotes were selected. Together they coded the focus group discussion and triangulated the data from the three sources (Creswell, 2007). The emergent themes from this research were grounded both empirically (from the data) and conceptually (from the analytical frameworks as outlined in the literature review) (Williams, 2012). The collaborative sorting and reflection on the data, as well as the triangulation of the three data sources helped to minimize researchers' biases.

\section{Findings}

\subsection{RQ 1: Manifestations of resistance to autonomous learning}

Four themes emerged from the three data sources that helped to answer to the first research question: How does student resistance to autonomous learning manifest in the classroom? They are: resistance to collaborative learning, unwillingness to 
independently use available language learning resources, resistance to metacognitive activities and resistance to the evaluation process.

\subsubsection{Resistance to collaborative learning}

Collaborative work is an intrinsic part of autonomous learning training. The teachers of English 101 considered teamwork an important strategy for minimizing student dependence on the teacher and promoting active participation in one's learning through peer co-construction of knowledge. This strategy minimizes excessive or even exclusive reliance on the teacher as well as forges real life intragroup relationships, conflicts, and negotiations. The students in the study, however, often did not perceive collaboration as a learning situation.

The diary entries and observation notes recorded various instances of resistance ranging from open to passive: students' vocalizing preference to work alone; sitting silently and not participating; sending text messages instead of participating; ignoring uncooperative team-members and taking on all the group work just to finish the project; negotiating with the teacher for a better group next time, or a separate higher grade for their input; or complaining openly to the teacher about their group. One expressed social preferences wanting to work with 'the lads from his village' (2TD18). The following email from a student shows the many reasons why students are unwilling to work in groups.

Dear Dr. X, I wanted to tell you after class, but you were kind of busy. I know simulations are supposed to be working with other members of the group, and you don't have a choice to choose who you want to be with. However, we're still in university and I have a small request. I would like to change my group, because: Roy acts like he's in charge, Jinanne is always texting and I can't understand anything Raji says. This is supposed to be an English project, but every time I speak in English, they change it to Arabic. We are getting graded for that and I don't want to lose points for their lack of English. Thank you, Student Jessica (1TD14).

The observation notes are filled with examples of students needing confirmation from their teacher about their performance or their ideas rather than discussing and negotiating the final choice with the team and relying on the judgment of their peers: 'Could you check our slogans? Which one should we choose?' (1TD15); 'Miss, whose logo do you like?' (2TD13). The effort of negotiation with teammates seemed to be unfamiliar or burdensome and students found difficulty connecting their collaboration efforts to their language development.

\subsubsection{Resistance to independent use of available language learning resources}

The course syllabus included a number of learning activities to be performed outside class. Students were encouraged to use resources, such as the English Language Centre, recommended online grammar activities, and Graded Readers at the university library to improve their reading skills, vocabulary, grammar and sentence 
structure skills. The Graded Readers were introduced at the beginning of the semester in the form of a guided activity, and after that students were expected to decide on their own how and when to use them. Most students soon dropped the attempt claiming that they were too busy with their major courses. While the teachers believed that such aspects of the course as vocabulary acquisition and grammar revision could be done by students at this level on their own, some students preferred teacher-prepared vocabulary lists and grammar exercises: 'Going to the library to borrow Graded Readers is not an effective way of building up vocabulary, because everybody knows we don't like to read and we won't read.' (FGS4); 'Instead the teacher could give us a list of words we need to know to pass the course.' (FGS47). As for grammar websites, only a small number of students, eleven out of sixty-eight (1TD, 2TD), reported in class accessing online grammar practice resources.

As part of the training for autonomous development, another activity was designed to familiarize students with how to find information in the library. The library task sheet had guiding questions. One teacher reported that a large majority of her students from the two sections returned to class with identical answers (2TD8). The incident showed that these students would rather use an 'easy opportunity' to copy from each other to complete a learning activity than exert the effort to work autonomously.

\subsubsection{Resistance to metacognitive activities}

Throughout the course, students were involved in awareness-raising activities that focused on their responsibility for language learning: use of available resources to suit their individual needs, discussions on various learning strategies needed for language acquisition, as well as keeping portfolios with personal action plans for reflection, self-evaluation and self-monitoring of their progress in the course.

One such metacognitive activity was regular debriefing sessions with the students at the end of each module. These sessions focused on their improvement in the course and the development of their skills: collaboration, autonomy, reflective learning, understanding the importance of English for their future, and the transferability of skills to other university courses. The two observers registered that in these sessions, students showed signs of impatience waiting for their written exam grade, which was to be given at the end of the debriefing session. Some students were observed not listening to the teacher and not willing to spend time to reflect on their work. Two students interrupted one teacher with very deliberate questions such as 'What are our grades, Miss?' (10N16).

The students kept a portfolio to reflect on their learning which included: their production during each simulation (for example logos, slogans, etc.), studentgenerated vocabulary sheets, process writing assignments, students' action plans and reflections on their progress in the course and self-evaluation sheets. Last minute compilation of the required portfolio entries, or photocopied tables of contents of other students, signaled to the teachers that the value of self-reflective learning which 
portfolios were meant to promote was not appreciated by some students and was perceived as an extra burden (1TD24, 2TD27).

\subsubsection{Resistance to the evaluation process}

In the course, the students encountered types of assessment that were unusual for them. In accordance with the course design, oral and written exams were in the form of simulations. There were no familiar vocabulary or grammar quizzes during the semester. Students' daily group work and portfolio were assessed. A student's questioned, 'When will we have a test, miss?' (1TD23) was interpreted by the researchers as an expectation of familiar regular grammar and vocabulary quizzes. The students had to readjust to new forms of assessment, with a reduced amount of product-oriented assessment and a greater amount of language-learning-as-a process assessment.

The portfolio grade was a new type of assessment for the students. As mentioned earlier, portfolio, as a metacognitive reflective exercise and evidence of students' progress through the course, was viewed by some students as a burden. Some students complained that the portfolio was just a compilation of papers, and it was unfair that they lost points for that activity (20N15). The students, however, became quite excited when a reflective portfolio task at the end of the semester asked them to evaluate their own language acquisition progress (1TD39). They were informed that their self-assessment would be calculated as part of the course grade. To support their grade, they had to provide evidence from their portfolio, which reflected their vocabulary and grammar skills development, as well as speaking and writing.

Another assessment strategy linked the grading rubric to students' reflections. In these reflective activities, students filled out a chart tracking the type and frequency of their grammar mistakes for each major graded assignment. The students were also asked to reflect on how or whether they developed strategies to address these weaknesses to improve their grammar. Initially, students were hostile to the rubric, which they found harsh and tried to negotiate the grading criteria. One student stated, 'Why are spelling and grammar mistakes such a big thing? Who cares? I won't need to write when I get a job.' (2TD24). By the middle of the semester, students began to understand the rationale of this assessment strategy. One student, happy with her grade for the second written exam, remarked, 'I don't have a single run-on problem. In my first essay I had twelve! I practiced at home before the exam.' (1TD39).

\subsection{RQ 2: Possible causes of resistance to autonomous learning}

One possible reason behind student resistance towards autonomous activities was identified as 'learning cultures that students bring to the classroom'. Another reason was linked to 'the perceptions of the place English 101 holds at the university and in their lives'. 


\subsubsection{Learning cultures that students bring to class}

The findings suggest that the learning cultures and experiences that students brought to the classroom clashed with the autonomous learning agenda promoted by the course. The two teachers reported in their diaries that it felt like they had to 'force students to be autonomous'. Many students resisted a mode of learning that they perceived to be different from their understanding of what learning should be.

During the debriefing sessions, students commented on past learning experiences and their expectations on 'what should happen in a classroom': 'Our education style does not encourage us to work in autonomy.' (FGS37); 'A student can't work without asking a teacher what to do.' (FGS57); 'Students need someone to force them to study. The teacher forces students to attend lessons so students don't miss important information.' (FGS4). These students brought in a passive acceptance of and disengagement from the learning process where the teacher fully determined and managed the learning situation. One student explained his attitude in class by his previous learning at school: 'Our English session in our [French] school was always a rest hour, "ntaesh al bizir"' (eating sunflower seeds-an Arabic idiom for doing something insignificant.) (2TD14).

Linked to students' passive attitude was the perception of the role of the teacher. Some of the student statements during the debriefing sessions were: 'The teacher is the most trusted source of information not ourselves.' (FGS7); 'The teacher has more experience and more accurate information.' (FGS50). For these students, the teacher was perceived to be the sole authority and giver of knowledge (Jin \& Cortazzi, 2017). In a study conducted in a similar context, Fleonova and Tassone (2016) identified that rather than engaging in a search for answers, the majority of students expected and preferred 'second-hand' information, that is, information prepared by the teacher in a concise form conveniently packaged for memorizing and passing exams.

When teachers assume a facilitative position, they appear to be functioning in a less authoritative role. The responsibility for the construction of knowledge and skills is delegated to the students through project and collaborative work. One student revealed to one of the observers, 'The teacher is not doing anything; we are doing everything.' (10N16). It is a common perception that the teacher does not know how to do the job (Jin \& Cortazzi, 2017), if he/she 'assumes a less authoritarian role, expects interactive group work..., does not encourage memorization or administer achievement tests, and generally acts as if the students should be responsible for their own learning' (Tarone \& Yule, as cited in Bloom, 2007, 90).

Bacha and Bahous (2011) reported that Lebanese students are conditioned to memorize and it is the teacher who provides the students with all the content that will be on the exams. Students in our context also seemed to have brought in a culture of grade-oriented expectations and 'learn for the test' studying styles, and when they encountered different types of assessment focusing on process rather than product, 
it caused questioning and uncertainty. After having received an assignment, students would often double-check with the teacher, 'Is it graded?' Students admitted that they did not want to put extra effort into something they did not perceive as having immediate benefit for them, i.e. the grade. The teachers documented in their diaries that after several days of group-work preparation for the simulation, students showed signs of unease, discomfort or uncertainty about the purpose of the activities and repeatedly asked, 'When will we have a test?'

Many students showed weaknesses when required to engage in metacognitive activities and it was not easy for them to present realistic goals in their action plans. In these action plans formulated at the beginning of the course on the basis of their diagnostic test, they were expected to reflect on their grammar and writing and design strategies to address their weaknesses. Many action plans consisted of a list of 'wishful thinking' statements, such as 'I will read more books' (FGS59), 'I will do grammar exercises using websites' (FGS16), and 'I will borrow books from the library' (FGS18). At the end of the semester during the focus group sessions, they revisited their action plans and admitted that such statements did not present a realistic strategy they would follow.

Some tensions came from the mismatch between teachers' understanding of what learning is versus students' understanding of what should happen in the classroom. The students did not perceive the simulation methodology, a strategy for promoting autonomy (Schormová, 2017) as an appropriate mode of learning. In simulationbased language courses the responsibility for tasks and projects, researching roles, selection of information and language expressions, and justifying one's choices is naturally delegated to students. The simulation methodology fell short of their expectations. Several students would inquire when the 'real' lesson would begin, 'When will we stop playing and start learning?' (20N10). As referred to in the literature review, some students resist simulations when they do not perceive such a methodology as 'serious' learning (Jung and Levitin, 2002). Similarly, students questioned the relevance of the simulation topics to their professional path. A biology student or an engineering student could not always understand how working on a business brochure or a mission statement for a photography club for example, was related to their major. This attitude would surface especially during the discussion with their teacher about their grades and performance.

Teacher-directed learning models that the majority of students are exposed to throughout their education have conditioned them to resist active learning strategies (Weimer, 2013). According to the Lebanese Association for Educational Studies, 'the school environment in both public and private schools is characterized by the dominance of teacher-centered teaching approaches and an almost complete absence of active learning approaches' $(2006,17)$. The findings suggest that one possible cause for resistance to autonomous learning activities stems from the teacher- 
centered learning environments and that the students brought into the English 101 classroom.

4.2.2. Students' perceptions of the place English 101 holds at the university and the role of English in their lives

Another source of resistance seems to come from students' perceptions of the English 101 course and the role of English in their lives. For many students, this English course had little immediate meaning other than a university curriculum requirement. In response to the teachers' appeal to put more effort into the course, one of the students replied, 'but, miss, ENGL101 grade is not part of the GPA' (1TD25). Several students upon hearing this gasped and showed signs of relief. Students just wanted to pass the course to get it out of the way. To prove their point that English is not important for their other courses, a student remarked, 'My teacher [in major] says that he doesn't care how good my English is in my essays. He says, I'm interested in your ideas.' (2TD16). Overall, students perceived their major courses as important to their career while all other university requirements in languages and humanities distracted them from obtaining a degree in their field. Students remarked, 'The English sessions are a waste of time because language can't be an academic course' (FGS3) and, 'We don't like the language courses, we want to study scientific courses.' (FGS23).

Instances of avoiding work in class ranged from not bringing homework, reading packs, notebooks or pens, to appearing in class just with two mobile phones and a pack of cigarettes (2TD3). Teacher 1 asked her 14 students to share the content of the phone messages they exchanged during the 50-minute lesson. The students showed enthusiasm for this activity and readily 'escaped' from the planned class task to share their messages. One exchange was between the cousins in the classroom forwarding the pictures of a baby cousin born in Greece. Some of the other exchanges included the following: 'shou bro weinak?' ['Where are you, bro?'], 'naatrinak' ['I'm waiting for you'], 'what are you doing?' 'How's the English hour?' 'Hello baby, how are you?' (Received five times by the same girl), 'there will be a surprise for you at 8', a joke from a friend, a phone recharge card number from a mother, and a few personal messages that students did not want to share (1TD28). In addition to coming to class unprepared, students were reliant on the teacher for explanations and would rather ask the teachers to explain the instructions, than read the instructions themselves.

Ambivalent attitudes towards the course stemmed from mixed signals that students received from the university culture. The data revealed that some students were reluctant to ameliorate their language because they were not asked for such language production standards in their other classes, nor did they see the importance or relevance of English 101 autonomous learning activities. Some representative quotes include: 'Miss, we use English only in our English class. In our other courses we use Arabic.' (2ON19); 'ENGL 101 is like a VAT on food.' (2TD7); 'We just want to pass the course.' (2TD7); 'Why portfolio?'(1TD30). Two studies conducted in the same 
institution found that although English is the medium of instruction at the university, the instructors' primary concern was to teach the content of their discipline and they asserted that they did not have the necessary training to 'teach English,' nor did they feel it was their job to do so.

Another possible cause of resistance is the ambiguity of the place English holds in the student's lives. For these students, satisfying the socio-economic requirements to become successful in Lebanese society firstly means obtaining a university degree. Most of the major universities in Lebanon teach in a foreign language and these university students need to grapple with the place these foreign languages may hold in their future. For many, further studies or jobs abroad are a viable and realistic option. Although English becomes a kind of passport to future success, students are often incapable of seeing the long term place English holds. Orr and Annous (2018) conducted a study in the same context to find out tertiary level students' perceptions of the language in education policy in Lebanon. Students acknowledged the benefits of English for their future. They viewed English as a necessary medium of instruction at all levels of education placing English as the best means for studying science, technology, business and the media. They also viewed English as important for their future education or careers abroad placing English as the conduit to emigration (Orr and Annous, 2018).

In our study, the students' perceptions oscillated between almost a unanimous claim that English would hold an important role in their future life voiced during class discussions and, on the other hand, statements like, 'Students only need Arabic to work in an Arab country,' (FGS8) or 'In Lebanon...connection with political people will give you an opportunity to have a good job even if you were failing your courses in university.' (FGS30). The findings suggest that their ambivalent attitude towards learning English in general impacted their preparedness to engage in autonomous activities in the English classroom.

\section{Discussion and Implications}

This study of resistance to autonomous learning reveals the complex nature of L2 learning and teaching where cultures of learning and broader social contexts need to be considered (Cortazzi \& Jin, 1997, 2013; Jin \& Cortazzi, 2017; Sonaiya, 2002). The cultural appropriateness of innovations in teaching methodology has often been viewed in the literature as a possible source of resistance (Blidi, 2017; Shamim, 1996). In this context, the students often questioned, negotiated and resisted 'the participation modes that their teacher [was] endeavoring to construct' (Miller \& Zuengler, 2011, 133) and which might have felt alien to the students. Students resisted collaborative learning, were unwilling to independently use available language learning resources, resisted metacognitive activities and resisted the evaluation process. The possible causes of resistance raised discussions about mismatches between students' expectations and the course design, the types of 
learning cultures that the students brought to the classroom, and the perceptions of the place English holds both at the university and later on in their lives.

Throughout the semester, some of the resistance appeared to be related to the conditioning students had received from their schooling. The findings showed that the students were primarily interested in the tangible achievements resulting from an exam-oriented education, and thus were mostly interested in short-term results, like their course grade, rather than the long-term second language learning goals. The teachers held the view that students needed to take more responsibility to become less teacher-dependent in their language learning, but for the students reliance on the teachers was perceived as an easier way to pass the course. The teacher-centered, product-oriented educational system the students in this study had been exposed to, created a set of cultural expectations somewhat removed from the process-oriented, autonomous teaching methodology in the language course under investigation.

While the main focus of this research centered on resistance to autonomous learning, the researchers noticed, as the course progressed, evidence of increased selfregulated functioning of the students. This progress was not linear and at different points throughout the semester students consistently showed resistance to collaborative and process-oriented tasks especially when they were not able to foresee or perceive how the learning activities were directly related to the course assessments (Canagarajah, 1993; Jing, 2006). This evidence that autonomous learning can be cultivated is encouraging, especially when there is a positive attitude among some university teachers and students majoring in education towards introducing active learning in Lebanese classrooms (Daouk, Bahous, \& Bacha, 2016). Training pre-service teachers and supporting the implementation of this type of methodology in schools eventually might bring about changes for a more learnercentered classroom culture in Lebanon.

This small-scale qualitative study began to probe the issues of resistance to autonomous learning in the Lebanese context. Investigating students' resistance allowed us to appreciate the complex and multi-dimensional aspects of autonomy. Further steps that will involve a larger empirical pool of students and teachers would yield more in-depth insights into issues such as processes of students' acculturation in language classrooms and teachers' cultural baggage that might color their attitudes and practices in an autonomous language classroom. Other steps would explore university cultures which directly or indirectly impact students' attitudes towards autonomous learning and how these institutions support individual teachers' efforts in promoting autonomy and collaborative learning.

\section{Conclusion}

In order to prepare for the challenges of both academic and professional life in the $21^{\text {st }}$ century, the learner should to be exposed to classroom practices that allow the development of skills such as autonomy. For a deeper understanding of autonomous learning in the L2 classroom and students' abilities to make decisions concerning 
their language learning, students' agency needs to be considered. Student autonomy is enacted within the framework determined and controlled by the teachers who are 'aiming for a particular kind of autonomy... a set of desirable behaviors matching the demands of the school and the society that the learner is about to enter' (Benson, 2009 , p. 25), and the students have no say in setting goals for themselves and therefore often do not see the relevance of these activities for their language acquisition or longer term life prospects. The implementation of autonomous learning should consider students' agency in their language development as a pivotal principle that shapes classroom interactions. Once students' agency in their own language learning is taken into consideration, the nature of the teaching and learning process will be transformed whereby the decision-making will no longer be top down. Students will play a more active role in other elements of the course, such as resource selection, evaluation processes, and setting longer term language learning goals. Curriculum developers and teachers should also be sensitive to students' contexts outside the classroom which may impact students' disposition toward taking charge of their language development.

\section{References}

[1] Akar, B. (2012). Teaching for Citizenship in Lebanon: Teachers talk about the civics classroom. Teaching and Teacher Education 28(3), 470-480.

[2] Annous, S., \& Nicolas, M.O. (2015). Academic territorial borders: A look at the writing ethos in business courses in an environment in which English Is a foreign language. Journal of Business and Technical Communication, 29(1), 93-111.

[3] Annous, S., Nicolas, M.O., \& Townsend, M. (2017). Territorial Borders and the Teaching of Writing in English: Lessons from Research at the University of Balamand. In L. Arnold, A. Nebel \& L. Ronesi, (Eds.), Emerging Writing Research from the Middle East-North Africa Region (pp. 85-114). Colorado: University Press.

[4] Bacha, N. N., \& Bahous, R. (2011). Foreign language education in Lebanon: A context of cultural and curricular complexities. Journal of Language Teaching and Research, 2(6), 1320-1328.

[5] Balçikanli, C. (2008). Fostering learner autonomy in EFL classrooms. Kastamonu Eĝitim Dergisi, 16(1), 277-284.

[6] Balçıkanlı, C. (2010). Learner autonomy in language learning: Student teachers' beliefs. Australian Journal of Teacher Education, 35, 90-103.

[7] Benson, P. (1997). The philosophy and politics of learner autonomy. In P. Benson \& P. Voller (Eds.), Autonomy and independence in language learning (pp. 18-34). London: Longman.

[8] Benson, P. (2001). Teaching and researching autonomy in language learning. Harlow: Longman.

[9] Benson, P. (2006). Autonomy in language teaching and learning. Language Teaching 40, 21-40. 
[10] Benson, P. (2009). Making sense of autonomy in language learning. In A. Barfield, S. Toogood\& R. Pemberton (Eds.), Maintaining control: Autonomy and language learning (pp. 13-26). Hong Kong: Hong Kong University Press.

[11] Benson, P., \& Voller, P. (Eds.). (1997). Autonomy and independence in language learning. London: Longman.

[12] Blidi, S. (2017). Collaborative learner autonomy: A mode of learner autonomy development. Springer.

https://link.springer.com/content/pdf/10.1007/978-981-10-2048-3.pdf

[13] Bloom, M. (2007). Tensions in a non-traditional Spanish classroom. Language Teaching Research 11(1), 85-102.

[14] Borg, S., \& Alshumaimeri, Y. (2019). Language learner autonomy in a tertiary context: Teachers' beliefs and practices. Language Teaching Research 23(1). 9-38.

[15] Canagarajah, A. S. (1993). Critical Ethnography of a Sri Lankan Classroom: Ambiguities in Student Opposition to reproduction Through ESOL. TESOL Quarterly 27(4), 601-626.

[16] Chik, A. (2018). Learner autonomy and digital practices. In A. Chik, N. Aoki, \& R. Smith, (Eds.), Autonomy in language learning and teaching: New research agendas (pp. 73-92). London: Palgrave.

[17] Chik, A., Aoki, N., \& Smith, R. (Eds.) (2018). Autonomy in language learning and teaching: New research agendas. London: Palgrave.

[18] Cortazzi, M., \& Jin, L. (1997). Cultures of Learning: Language Classrooms in China. In H. Coleman (Ed.), Society and the language classroom (pp.169206). Cambridge: Cambridge University Press.

[19] Cortazzi, M., \& Jin, L. (2013). Introduction: Researching cultures of learning. In M. Cortazzi \& L. Jin (Eds.), Researching cultures of learning: International Perspectives on language learning and education. (pp. 1-17). London: Palgrave Macmillan.

[20] Creswell, J. W. (2007). Qualitative inquiry and research design: Choosing among five approaches (2nd ed.). Thousand Oaks, CA: Sage.

[21] Crookall, D., \& Oxford R.L. (Eds.). (1990). Simulation, gaming, and language learning. New York: Newbury House Publishers.

[22] Daouk, Z., Bahous, R., \& Bacha, N.N. (2016). Perceptions on the effectiveness of active learning strategies. Journal of Applied Research in Higher Education, 8(3), 360-375.

[23] Dafei, D. (2007). An exploration of the relationship between learner autonomy and English proficiency. Asian EFL Journal. 24. 1-23.

[24] Fleonova 0., \& Tassone, G. (2016). Collaborative Action Research as a Tool for Teachers' Professional Development. Hawliyat, 17, 73-101.

[25] Garcia-Carbonell, A., Rising, B., Montero, B., \& Watts, F. (2001). Simulation/gaming and the acquisition of communicative competence in another language. Simulation \& Gaming, 32(4), 481-491. 
[26] Gill, S. K., \& Kirkpatrick, A. (2013). English in Asian and European higher education. In C. Chapelle (Ed.), The Encyclopedia of Applied Linguistics. Oxford, UK: Blackwell.

[27] Harmer, J. (2001). The Practice of English Language Teaching (3 $\left.{ }^{\text {rd }}\right)$. London: Longman.

[28] Hiemstra, R., \& Brockett, R. (1994). Resistance to self-direction in learning can be overcome. In R. Hiemstra \& R. Brockett (Eds.) Overcoming Resistance to Self-Direction in Adult Learning (pp. 89-92). San Francisco: Jossey-Bass Publishers.

[29] Hill, J. (2009). Student Evaluation of a Simulation-based Course. Paper presented at the ISAGA Conference, Singapore.

[30] Holec, H. (1981). Autonomy and Foreign Language Learning. Oxford: Pergamon.

[31] Holliday, A. (2003). Social autonomy: Addressing the dangers of culturalism in TESOL. In D. Palfreyman \& R. Smith (Eds.), Learner autonomy across cultures (pp. 110-126). New York: Palgrave.

[32] Jin, L., \& Cortazzi, M. (2017). Practising cultures of learning in internationalising universities, Journal of Multilingual and Multicultural Development, 38(3), 237-250, DOI: 10.1080/01434632.2015.1134548

[33] Jing, H. (2006). Learner resistance in metacognition training? An exploration of mismatches between learner and teacher agendas. Language Teaching Research 10(1), 95-117.

[34] Jones, K. (1982). Simulations in language teaching. Cambridge: Cambridge University Press.

[35] Jones, K. (1995). Simulations: A handbook for teachers and trainers (3rd). New Jersey: Nicholas Publishing.

[36] Jones, R.H. (2018). Learning through technology. In A. Burns \& J. C. Richards (Eds.), The Cambridge Guide to Learning English as a Second Language (pp. 319-326). Cambridge: Cambridge University Press.

[37] Jung, C.S.Y, \& Levitin, H. (2002). Using a simulation in an ESL classroom: A descriptive analysis. Simulation and Gaming, 33(3), 367-375.

[38] Keeney-Kennicutt, W., Gunersel, A., \& Simpson, N. (2008). Overcoming Student Resistance to a Teaching Innovation. International Journal for the Scholarship of Teaching and Learning, 2(1). doi.org/10.20429/ijsotl.2008.020105

[39] Little, D. (2005). The Common European Framework and the European Language Portfolio: involving learners and their judgements in the assessment process. Language Testing 22(3), 321-336.

[40] Little, D. (2003). Learner autonomy and public examinations. In D. Little, J. Ridley \& E. Ushioda (Eds.) Learner autonomy in the foreign language classroom: Teacher, learner, curriculum and assessment (pp. 223-233). Dublin: Authentik. 
[41] Little, D., Ridley, J., \& Ushioda, E. (Eds.). (2003). Learner autonomy in the foreign language classroom: Teacher, learner, curriculum and assessment. Dublin: Authentik.

[42] Lebanese Association for Educational Studies. (2006). National educational strategy in Lebanon. Retrieved from:

http://www.laes.org/upload//editor_upload/file/Reports/strategicplanle b/ Vision\%20Document\%20\%20English.pdf

[43] Maharaj, N. (2016). Using field notes to facilitate critical reflection. Reflective Practice, 17(2) 114-124. DOI: 10.1080/14623943.2015.1134472

[44] Ministry of Education and Higher Education. (2016). Private Universities and Institutions. Retrieved from the Lebanese Ministry of Education and Higher Education website: http://www.higher-edu.gov.lb/english/Private_ Univ.htm

[45] Miller, E., \& Zuengler, J. (2011). Negotiating access to learning through resistance to classroom practice. The Modern Language Journal, 95(Supplementary Issue), 130-147.

[46] Nicolas, M.O., \& Annous, S. (2013). Assessing WAC elements in business syllabi. Business Communication Quarterly, 76(2) 172 -187.

[47] Nicolas, M.O., \& Blair, J. (2018). Simulation as a key to successful English language acquisition in an EFL Arabic-speaking environment. International Journal of Multidisciplinary Thought, 7(1), 143-156.

[48] Nunan, D. (1997). Designing and adapting materials to encourage learner autonomy. In P. Benson \& P. Voller (Eds.), Autonomy and independence in language learning (pp. 204-214). London: Longman.

[49] Orr, M., \& Annous, S. (2018). There is no alternative! Student perceptions of learning in a second language in Lebanon. Journal of Language and Education, 4(1), 79-91.

[50] Oxford, R. (2003). Toward a more systematic model of L2 learner autonomy. In D. Palfreyman \& R. Smith (Eds.), Learner Autonomy across cultures: Language Education Perspectives (pp.75-91). Basingstoke: Palgrave.

[51] Oxford, R. (2017). Teaching and Researching Language Learning Strategies: Self-Regulation in Context (2nd ed.). New York: Routledge.

[52] Palfreyman, D. (2003). Introduction: Culture and learner autonomy. In D. Palfreyman \& R. Smith (Eds.), Learner Autonomy across cultures: Language Education Perspectives (pp.75-91). Basingstoke: Palgrave.

[53] Palfreyman, D., \& Smith, R. (Eds.). (2003). Learner Autonomy across cultures: Language Education Perspectives. Basingstoke: Palgrave.

[54] Pawlak, M., Mystkowska-Wiertelak, A., \& Bielak, J. (Eds.). (2017). Autonomy in Second Language Learning: Managing the Resources. Springer, Cham.

[55] Pennycook, A. (1997). Cultural alternatives and autonomy. In P. Benson \& P. Voller (Eds.), Autonomy and independence in language learning (pp. 3553). London: Longman. 
[56] Po-Ying, C. (2007). How students react to the power and responsibility in being decision makers in their own learning? Language Teaching Research, 11(2), 225-241

[57] Rose, H. (2012). Language learning strategy research: Where do we go from here? Studies in Self-Access Learning Journal, 3(2), 137-148.

[58] Salies, T. G. (2002). Promoting strategic competence: What simulations can do for you. Simulation \& Gaming, 33(3), 280-283.

[59] Schmenk, B. (2005). Globalizing learner autonomy. TESOL Quarterly, 39(1), 107-118.

[60] Schormová, Z. (2017). Simulation as a Strategy for Enhancing Learner Autonomy in Developing Communicative Competence in ESP. In M. Pawlak, A. Mystkowska-Wiertelak \& J. Bielak (Eds.), Autonomy in Second Language Learning: Managing the Resources (pp.35-50). Springer, Cham.

[61] Shamim, F. (1996). Learner resistance to innovation in classroom methodology. In H. Coleman (Ed.), Society and the language classroom (pp. 105-121). Cambridge: Cambridge University Press.

[62] Smith, R. (2008). Learner autonomy. ELT Journal, 62(4), 395-397.

[63] Sonaiya, R. (2002). Autonomous language learning in Africa: A mismatch of cultural assumptions. Language Culture and Curriculum. 15(2), 106-116. Doi:10.1080/07908310208666637

[64] Stover, S., \& Holland, C. (2018). Student resistance to collaborative learning. International Journal for the Scholarship of Teaching and Learning, 12(2), article 8 doi.org/10.20429/ijsotl.2018.120208

[65] Tolman, A. O. \& Kremling, J. (2017). Why Students Resist Learning: A Practical Model for Understanding and Helping Students. Sterling, VA: Stylus Publishing

[66] Vetter, A., Reynolds, J., Beane, H., Roquemore, K., Rorrer, A., \& ShepherdAllred, K. (2012). Reframing resistance in the English classroom. English Journal, 102(2), 114-121.

[67] Walton, J. D. (2011). Dissonance in the critical classroom: The role of social psychological processes in learner resistance. College Student Journal, 45(4), 769-785.

[68] Weimer, M. (2013). Learner-centred teaching: Five key changes to practice ( $2^{\text {nd }}$ ed.). San Francisco, CA: Jossey-Bass.

[69] Williams, J. P. (2012). Emergent themes. In L.M.Given (Ed.), The Sage encyclopedia of qualitative research methods (p. 249). Thousand Oaks: Sage Publications, Inc.

[70] Zakharia, Z. (2011). Language-in-education policies in contemporary Lebanon: Youth perspectives. In O. Abi-Mershed (Ed.), Trajectories of education in the Arab world: Legacies and challenges (pp. 157-184). London: Routledge. 